\title{
Mandating Syndromic Surveillance Reporting from Emergency Departments: The Washington Experience
}

\author{
Amanda D. Morse, Natasha Close*, Cynthia Harry and Kevin Wickersham
}

Office of Communicable Disease Epidemiology, Washington State Department of Health, Shoreline, WA, USA

\section{Objective}

To protect syndromic surveillance data reporting from emergency departments in Washington State beyond the cessation of Meaningful Use incentive funding in 2021.

\section{Introduction}

As syndromic surveillance reporting became an optional activity under Meaningful Use Stage 3 and incentive funds are slated to end completely in 2021, Washington State sought to protect syndromic reporting from emergency departments. As of December 2016, Washington State emergency departments had received $\$ 765,335,529.40$ in incentive funding, with facilities receiving an average of three payments of $\$ 479,974.04$ each. ${ }^{1}$

Considering the public health importance of syndromic surveillance reporting and the fiscal impact of mandatory reporting, the Washington State Department of Health (WA DOH) sought a new statute to require reporting from all emergency departments within the state.

\section{Methods}

Stakeholder negotiations occurred in four distinct phases: initial outreach to gauge support for the proposed legislation and solicit comments on items for inclusion in the bill language (April to October 2016), negotiations on the proposed text (October 2016 to January 2017), sustained contact with key groups during the legislative session (January to May 2017), and targeted messaging and comment solicitation to inform the development of the administrative codes to accompany the statute (May 2017 to March 2018) (Figure 1). WA DOH secured funding from the Washington Traffic Safety Commission (WTSC) to hire a designated staff member to coordinate and lead the syndromic surveillance program's legislative agenda.

\section{Results}

During the first phase, WA DOH contacted a diverse group of stakeholders, including 7 state agencies, 5 data provider groups, 3 professional associations, 3 public health non-profits, 35 local health jurisdictions, and 29 Tribal Organizations to provide information on syndromic surveillance and gauge interest in the proposed legislation. Key partners included the WTSC, the Washington State Hospital Administration (WSHA), the Washington Poison Center (WAPC), and several large to medium-sized local health jurisdictions (LHJs).

Early stakeholder negotiations indicated broad support among local health jurisdictions, state agencies, programs handling violence and injury topics, communicable disease specialists, the Department of Labor and Industries, and the Office of Financial Management; however, support from data providers was more cautious. Early relationship-building and maintaining frequent contact was key to securing support from data providers and allowed WA DOH to draft a mid-session amendment to the bill granting greater data access for providers and clarifying the foundational fee structure for data distribution.

During the second phase of outreach and communication, areas of more intense negotiation included data access levels for providers, timeliness of data availability, and the proposed inclusion of a "sundown clause" which would end the effective period of the statute when federal incentive spending expired.

WA DOH secured bipartisan co-sponsorship for the bill in the Washington State Senate and stakeholder negotiations continued throughout the legislative session (January-May 2017). Common concerns from stakeholders and legislators included the maintenance of patient privacy, the costs associated with participation for emergency departments, and data sharing agreements with facilities providing syndromic data.

The bill passed unanimously out of the Washington State Senate and with broad bipartisan support out of the Washington State House. Governor Jay Inslee signed the bill into law on May 5, 2017 and WA DOH has continued negotiations as they develop the administrative codes to accompany the statute.

\section{Conclusions}

Broad and sustained interactions with a diverse group of stakeholders, as well as willingness to compromise on data sharing and cost issues with providers, was key to Washington State's successful effort to mandate syndromic surveillance reporting from emergency departments.

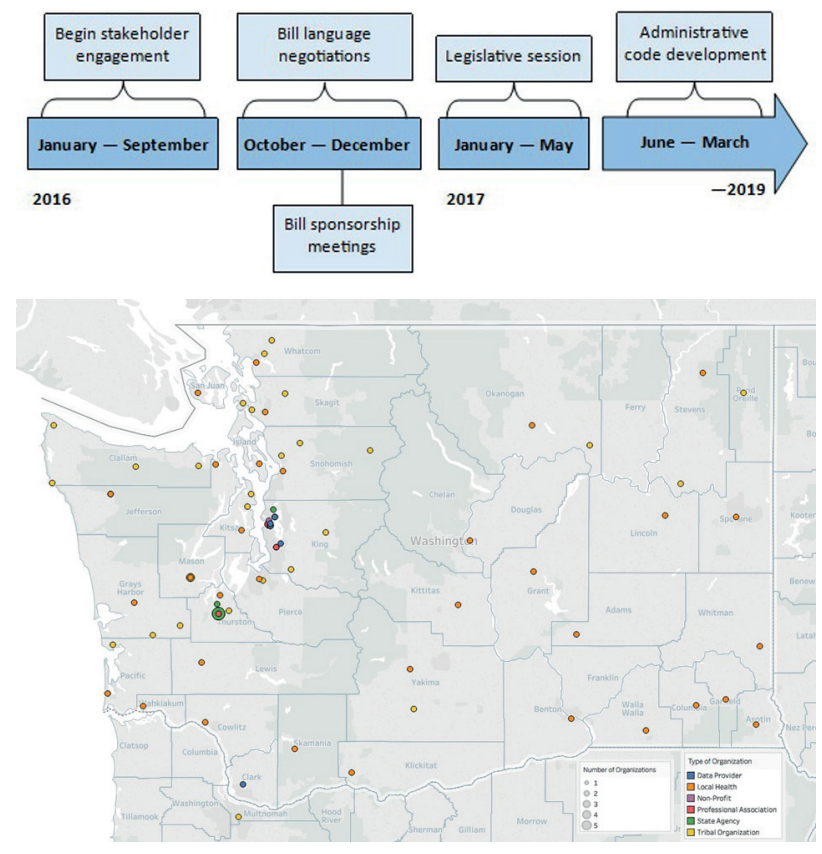

Keywords

Policy; Emergency Department; Community Collaboration; Meaningful Use; Meaningful Use 


\section{ISDS 2018 Conference Abstracts}

\section{Acknowledgments}

The authors would like to thank our bill co-sponsors; the Washington Traffic Safety Commission; the Washington State Hospital Association; Washington Poison Center; the Whatcom County Department of Health, Public Health Seattle-King County, Tacoma-Pierce County Public Health, the Benton-Franklin Health District, Drs. Cathy Wasserman and Scott Lindquist, and our other legislative partners. Particular gratitude is due to the Washington Traffic Safety Commission for funding RHINO's outreach and legislative efforts.

\section{References}

1. Medicare and Medicaid Incentive Provider Payments By State, Program Type and Provider Type January 2011 to December 2016. Centers for Medicare and Medicaid. https://www.cms.gov/Regulationsand-Guidance/Legislation/EHRIncentivePrograms/Downloads/ December2016_PaymentsbyStateProgramandProvider.pdf Last accessed: 11 September 2017

\section{*Natasha Close}

E-mail: natasha.close@doh.wa.gov 